\title{
Reconexão entre produção e consumo de alimentos e a política territorial de desenvolvimento rural no Brasil
}

\author{
Anelise Graciele Rambo \\ Universidade Federal do Rio Grande do Sul - Porto Alegre - Rio Grande do Sul - \\ Brasil \\ Tanise Dias Freitas \\ Universidade de Santa Cruz do Sul - Santa Cruz do Sul - Rio Grande do Sul - \\ Brasil
}

\section{Resumo}

As tradicionais estratégias de desenvolvimento rural têm desconsiderado os circuitos curtos de comercialização, baseados na interação face a face, nas relações de confiança entre produtor e consumidor e atribuem o conceito de mercado apenas aos circuitos longos. Cada vez mais vem sendo reconhecida a importância da reconexão entre a produção e o consumo de alimentos no âmbito acadêmico, social e político. Essa reconexão tem repercussões diretas sobre questões de segurança e soberania alimentar, tanto por parte do agricultor, quanto do consumidor. Vale ressaltar que na construção e fortalecimento destes circuitos locais de produção-consumo, o papel do consumidor é essencial. Com base nessas considerações, enfatizamos que apesar de a política territorial brasileira ter contribuído para o estabelecimento ou mesmo fortalecimento de circuitos curtos de comercialização, isto não representa um objetivo ou princípio explícito da política. Consequentemente, o consumidor tem sido desconsiderado enquanto um ator central na dinâmica territorial de desenvolvimento rural. Pretende-se assim ilustrar estas observações a partir da análise de documentos oficiais do Programa Desenvolvimento Sustentável de Territórios Rurais (Pronat) e do Programa Territórios da Cidadania (PTC), dos Plano Territorial de Desenvolvimento Territorial Sustentável (PTDRS) e dos projetos executados em três territórios rurais e da cidadania localizados na região Sul do Brasil. Enquanto resultados, o estudo evidenciou que, apesar da política territorial propor a superação do horizonte estritamente setorial, as dinâmicas de desenvolvimento implementadas carecem avançar nesse aspecto, promovendo maior aproximação campo-cidade e produtor-consumidor, o que incluiu a criação de institucionalidades que amparem tais dinâmicas.

Palavras-chave: Circuitos curtos de comercialização. Política territorial. Desenvolvimento rural, Consumidor. Segurança alimentar.

Reconnection between food production and consumption and the territorial policy of rural development in Brazil 


\begin{abstract}
The traditional rural development strategies have disregarded the short circuits of commercialization, based on face-to-face interaction, in trust relationships between producer and consumer and attribute the market concept only to long circuits. Increasingly it is being recognized the importance of the reconnection between production and consumption of food in the academic, social and political spheres. This reconnection has direct repercussions on food security and sovereignty issues, both by the farmer and the consumer. It is noteworthy that in the construction and strengthening of these local circuits of production-consumption, the consumer's role is essential. Based on these considerations, we emphasize that although Brazilian Territorial Policy has contributed to the establishment or even the strengthening of short marketing circuits, this does not represent an explicit objective or principle of policy. Consequently, the consumer has been disregaded as a central actor in the territorial dynamics of rural development. It is intended to illustrate these observations from the analysis of official documents of the Sustainable Development of Rural Territories Program (Pronat) and the Citizenship Territories Program (PTC), the Territorial Plan for Sustainable Territorial Development (PTDRS) and the projects implemented in three rural areas and citizenship Located in the southern region of Brazil. As results, the study showed that, despite the territorial policy proposing the overcoming of the strictly sectorial horizon, the development dynamics implemented need to advance in this aspect, promoting a greater approach to the field-city and Producer-Consumer, which included the creation of institutionalities that supported such dynamic.

Keywords: Short marketing circuits. Territorial policy. Rural development. Consumer. Food security.

\section{Reconexión entre la producción y el consumo de alimentos y la política territorial de desarrollo rural en Brasil}

\title{
Resumen
}

Las estrategias de desarrollo rural tradicionales han hecho caso omiso de los circuitos cortos de comercialización, basados en la interacción cara a cara, las relaciones de confianza entre el productor y el consumidor, y atribuyen el concepto de mercado sólo a los circuitos largos. Cada vez más se ha reconocido la importancia de la reconexión entre la producción y el consumo de alimentos en el ámbito académico, social y político. Esta reconexión tiene repercusiones directas en las cuestiones de seguridad y soberanía alimentaria, tanto por parte del agricultor como del consumidor. Cabe destacar que en la construcción y fortalecimiento de estos circuitos locales de producción-consumo, el papel del consumidor es esencial. Sobre la base de estas consideraciones, subrayamos que, aunque la política territorial brasileña ha contribuido al establecimiento o incluso al fortalecimiento de los corto circuitos de comercialización, esto no representa un objetivo o principio explícito de Política. En consecuencia, el consumidor ha sido ignorado como actor central en la dinámica territorial del desarrollo rural. El objetivo es ilustrar estas observaciones del análisis de los documentos oficiales del Programa de Desarrollo Sostenible de los Territorios Rurales (Pronat) y el Programa de Territorios de Ciudadanía (PTC), el Plan Territorial para el Desarrollo Territorial Sostenible (PTDRS) y los proyectos implementados en tres territorios rurales y ciudadanía ubicados en la región sur de Brasil. Como resultado, el estudio demostró que, a pesar de que la política territorial proponía la superación del horizonte estrictamente sectorial, la dinámica de desarrollo implementada debe avanzar en ese aspecto, promover una aproximación más estrecha entre campo-ciudad y el productor-consumidor, que incluía la creación de institucionalidades que apoyaran tales dinámicas. 
Palabras clave: Circuitos cortos de comercialización. Política territorial. Desarrollo rural. Consumo. Seguridad alimentaria.

\section{Introdução}

Os dados do Relatório Anual das Nações Unidas sobre Segurança Alimentar e Nutricional de 2017 indicaram que, após quase uma década de declínio, o número de pessoas afetadas pela fome no mundo aumentou novamente, havendo 815 milhões de habitantes nessa situação e $11 \%$ da população mundial sofrendo de desnutrição crônica em 2016. Em 2017, 124 milhões necessitaram de assistência alimentar de emergência em comparação com os 108 milhões de 2016. Outro problema que merece especial atenção é o da obesidade. Segundo o mesmo relatório da Organização das Nações Unidas (ONU), há 641 milhões de adultos obesos, o que corresponde a $13 \%$ do total de adultos do planeta. Quanto às crianças, esse número é de 41 milhões menores de 5 anos com sobrepeso e ainda, 613 milhões (cerca de 33\% do total), de mulheres em idade reprodutiva afetadas por anemia.

Pode-se afirmar então que um dos maiores desafios a ser enfrentado desde agora e pelas próximas décadas refere-se a como assegurar à população mundial crescente, que deverá alcançar 10 bilhões de pessoas até 2050, não apenas o acesso a alimentos suficientes, mas alimentos com qualidade e diversidade de modo a satisfazer suas necessidades nutricionais. Por sua vez, há estimativas que apontam que a produção de alimentos deverá aumentar em 50\% ao nível global para atender este crescimento populacional.

Nesse cenário, o Brasil tem despontado como o país com grande potencial quanto ao crescimento na produção de alimentos. O Departamento de Agricultura dos Estados Unidos (USDA) calcula que o país deva alavancar sua produção em cerca de $40 \%$, enquanto que países como China (15\%), a União Europeia (12\%), Estados Unidos (10\%), Canadá (9\%), Austrália ( $9 \%$ ) e Rússia (7\%) também devem crescer significativamente até 2027.

O Relatório Projeções do Agronegócio - Brasil 2016/17 a 2026/27, elaborado pelo Ministério da Agricultura, Pecuária e Abastecimento (MAPA), estima que a produção de grãos deva crescer $24 \%$ no período, destacando-se milho, soja e trigo. Já a produção de carnes (bovina, suína e aves) deverá ter um crescimento de $28 \%$. Diante de tais projeções, a questão que emerge é: que tipo de alimentação estará sendo produzida para a população brasileira e mundial? Não seria este padrão de consumo um aspecto-chave para o aumento da obesidade no mundo? Não estaríamos fomentando o mesmo modelo que tem gerado guerras e conflitos e que, aliadas a fenômenos naturais extremos como secas e enchentes, tem gerado migrações em massa e aumento da fome no mundo?

Sem dúvida, os circuitos longos que configuram os impérios alimentares, são capazes de atender a demanda mundial de alimentos. No entanto, as tradicionais estratégias de desenvolvimento rural têm desconsiderado os circuitos curtos de comercialização, baseados na interação face a face, nas relações de confiança entre produtor e consumidor no âmbito acadêmico, social e político.

Nesse sentido, intensificam-se as discussões acerca dos circuitos curtos e descentralizados de comercialização (MARSDEN, BANKS, BRISTOW, 2000; GAZOLLA, 
SCHNEIDER, 2013; 2017; PLOEG, 2008) que aproximam produção e consumo, tais como feiras de produtores, entrega de cestas, pequenas lojas de produtores, venda nas propriedades decorrentes do agroturismo, mercados institucionais, dentre outras. Diante dessa alternativa, a agricultura familiar assume papel fundamental, já que é responsável por cerca de $80 \%$ da produção mundial de alimentos, segundo a ONU.

Retornando ao debate internacional, vale destacar que o acesso à alimentação compõe a Declaração Universal dos Direitos Humanos, em seu artigo 25, a qual reconhece que toda pessoa tem direito a um nível de vida adequado que assegure, assim como a sua família, saúde, bem-estar e, em especial, alimentação. Recentemente, os Objetivos do Desenvolvimento Sustentável (ODS) aproximaram ainda mais os temas fome, segurança alimentar e nutricional e agricultura, expresso no objetivo 2: "Acabar com a fome, alcançar a segurança alimentar e melhoria da nutrição e promover a agricultura sustentável”.

Frente ao exposto, acredita-se que a perspectiva territorial do desenvolvimento rural e, mais especificamente, as políticas territoriais têm o potencial de abarcar as dimensões da segurança alimentar acima discutidas, promovendo dinâmicas de desenvolvimento que, ao aproximarem produção e consumo, serão capazes de promover soberania alimentar, maior equidade social e menos impactos ambientais. O que se pretende evidenciar é que, apesar de a política territorial brasileira ter possibilitado a criação ou fortalecimento de circuitos curtos de comercialização, este não consistia em um objetivo explícito da mesma.

Apesar da paralisação da política territorial brasileira a partir de 2017, julga-se importante tecer tais considerações, dados os avanços alcançados pela referida política no que concerne ao empoderamento dos atores locais/regionais e a valorização da diversidade e das especificidades territoriais.

Assim, o presente artigo estrutura-se em sete seções a contar com esta introdução. A segunda parte trata da política territorial brasileira e suas dinâmicas, destacando como a perspectiva rural do desenvolvimento avança com a questão dos territórios. Na terceira seção, destaca-se a abordagem dos circuitos curtos de comercialização como uma proposta teórica para analisar e compreender o desenvolvimento territorial rural, proposto a partir da política pública. Na sequência, apresenta-se a metodologia do trabalho que é fruto de um projeto de pesquisa custeado pelo Conselho Nacional de Desenvolvimento Científico e Tecnológico (CNPq). Posteriormente, tem-se a análise de projetos rurais entendidos como experiências de circuitos curtos de comercialização com potencial de promoção do desenvolvimento territorial. Por fim, seguem as considerações finais e referências que embasaram os presentes apontamentos.

\section{A política territorial brasileira e as dinâmicas territoriais}

Não se pode negar que a perspectiva territorial do desenvolvimento é um avanço importante no que se refere à promoção do desenvolvimento, em especial, do desenvolvimento rural, já que as políticas públicas com essa perspectiva focam quase que exclusivamente nos espaços rurais. Sabourin, Massardier e Sotomayor (2016) destacam que as referidas políticas consideram as especificidades de cada território em oposição ao enfoque vertical que divide a ação pública em setores. 
Valorizam-se as características e os recursos de cada território, o qual seria o local de definição e solução de problemas públicos. Supõem também um tratamento localizado das questões e, portanto, o desenvolvimento de uma pluralidade de atores envolvidos na produção de um laço político e social.

O princípio da territorialização das políticas públicas basear-se-ia em três pontos: 1) o serviço ou o bem público não é distribuído de maneira uniforme pela autoridade central; 2) a tentativa de aproximar usuários ou beneficiários na tomada de decisão sobre os problemas; 3) o território não é definido administrativamente, mas de acordo com uma dinâmica especificamente territorial (SABOURIN; MASSARDIER; SOTOMAYOR, 2016).

$\mathrm{Na}$ concepção de Brandão (2008), promover desenvolvimento implica no envolvimento e legitimação de ações capazes de romper com o status quo anterior, em que também estejam envolvidas tensões, escolha de alternativas e construção de trajetórias históricas, buscando horizontes temporais de curto, médio e longo prazos. Para o autor, esse processo de transformação deve ser promovido simultaneamente nas dimensões produtiva, social, tecnológica (e outras que houver) e nas escalas espaciais locais, regionais, nacionais, globais, etc. para que permita maior fortalecimento da autonomia de decisão e amplie o espaço de ação dos sujeitos sociais.

Sob semelhante perspectiva, a proposta territorial de desenvolvimento rural sustentável, arquitetada pelo Estado Brasileiro, envolvia uma visão integradora de espaços, atores sociais, mercados e políticas públicas de intervenção. Propõem-se o desenvolvimento de soluções que contemplem combinações entre as diversas dimensões do desenvolvimento sustentável: econômica, sociocultural, políticoinstitucional e ambiental (BRASIL, 2004).

A referida política surge no Brasil no âmbito rural, dentro do Ministério do Desenvolvimento Agrário (MDA), com a criação da Secretaria do Desenvolvimento Territorial (SDT), implementando o Programa Desenvolvimento Sustentável de Territórios Rurais (Pronat), criado em 2003 e Programa Territórios da Cidadania (PTC), criado em 2008.

No Pronat, o território é entendido enquanto um espaço físico, geograficamente definido, compreendendo cidades e campos, caracterizado por critérios multidimensionais (ambiente, economia, sociedade, cultura, política e instituições) e uma população com grupos sociais distintos onde se pode distinguir um ou mais elementos que indicam identidade e coesão social, cultural e territorial. Já o território rural seria aquele espaço onde os critérios multidimensionais que o caracterizam apresentam a predominância de elementos rurais (BRASIL, 2004).

O objetivo geral do Pronat consistia em promover e apoiar iniciativas das institucionalidades representativas dos territórios rurais que objetivassem 0 incremento sustentável nos níveis de qualidade de vida da população rural. A seleção dos territórios rurais para ações do Pronat tiveram por base as microrregiões geográficas que apresentaram densidade demográfica menor que 80 hab $/ \mathrm{km}^{2}$ e população média por município de até 50.000 habitantes, bem como a presença de agricultores familiares, famílias assentadas e famílias de trabalhadores acampadas (BRASIL, 2004). Com base nos critérios estabelecidos pela SDT, instituiu-se 239 territórios rurais (BRASIL, 2010), conforme figura 1 que segue. 
Figura 1. 239 territórios apoiados pela SDT/MDA

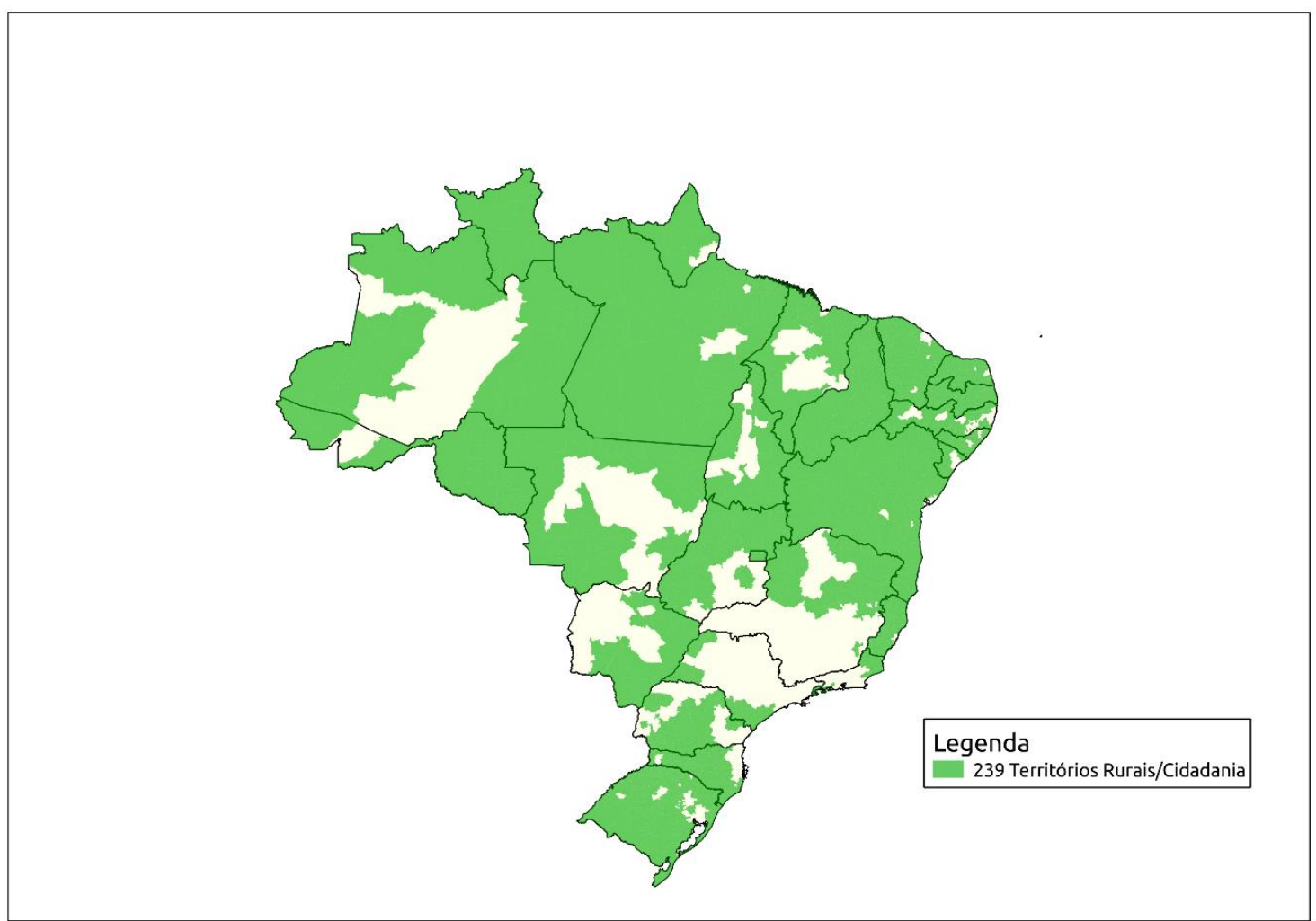

Fonte: SGE, 2014.

A estrutura organizacional dos territórios sustentou-se pelos Colegiados de Desenvolvimento Territorial (Codeter), os quais deveriam ter em sua composição representantes das esferas municipal, estadual e federal e da sociedade, devendo haver no mínimo 50\% de participação da sociedade civil. Ainda, os territórios demandavam uma representatividade diversa e plural dos atores sociais relacionados ao desenvolvimento rural. Ao Codeter coube deliberar e propor ações para o desenvolvimento sustentável dos territórios, além de articular políticas públicas, realizar o planejamento das ações e definir os programas e projetos que deveriam compor o Plano Territorial de Desenvolvimento Territorial Sustentável (PTDRS).

Wesz Júnior e Leite (2010) sintetizam que, em 2003, as linhas de ação baseavam-se em duas modalidades do Pronaf: (a) Infraestrutura e Serviços Municipais e (b) Capacitação dos Agricultores Familiares. Essas duas linhas deixaram de fazer parte do Pronaf e passaram a compor o Pronat através das funções: Apoio a Projetos de Infraestrutura e Serviços em Territórios Rurais e Capacitação de Agentes de Desenvolvimento. Paralelamente, duas outras ações compuseram o Pronat, mesmo não agregadas na sua matriz orçamentária: a) Assistência Financeira Mediante Emendas Parlamentares e b) Projeto Dom Helder Câmara (PDHC) Desenvolvimento Sustentável para os Assentamentos da Reforma Agrária no Semiárido do Nordeste.

Quanto ao volume de recursos contratados, estes passaram de $\mathrm{R} \$ 82,7$ milhões em 2003, para $\mathrm{R} \$ 264,7$ milhões em 2007, o que correspondeu a um crescimento de $272 \%$. De 2007 a 2008 ocorreu uma queda no valor contratado de cerca de $\mathrm{R} \$ \mathbf{4 0}$ milhões, vinculada à diminuição dos recursos oriundos das emendas parlamentares. Enquanto as demais linhas ampliaram o seu orçamento em 2008, as 
emendas territoriais apresentaram uma baixa de 50\% em comparação com o ano anterior (WESZ JÚNIOR; LEITE, 2010).

Já o Programa Territórios da Cidadania (PTC) é resultado da constatação acerca das significativas desigualdades socioeconômicas entre os próprios territórios rurais. A prioridade do PTC consistia em atender territórios que apresentam baixo acesso a serviços básicos, índices de estagnação na geração de renda e carência de políticas integradas e sustentáveis para autonomia econômica. O objetivo maior consiste na superação da pobreza e geração de trabalho e renda no meio rural por meio de uma estratégia de desenvolvimento territorial sustentável (BRASIL, 2011, grifo nosso).

A partir do conceito de território adotado pelo Pronat, o PTC acrescenta novos critérios de seleção dos Territórios de Cidadania dentre os territórios rurais, com presença de um por estado da federação em 2008 e dois em 2009. Os critérios mencionados são: (a) menor Índice do Desenvolvimento Humano (IDH); (b) maior concentração de agricultores familiares e assentados da Reforma Agrária; (c) maior concentração de quilombolas e indígenas; (d) maior número de beneficiários de programas federais de transferência de renda; (e) maior número de municípios com baixo dinamismo econômico; (f) maior organização social; (g) menor Índice de Desenvolvimento da Educação Básica (Ideb) (WESZ JÚNIOR; LEITE, 2010). Desse modo, o PTC abarcou 120 territórios da cidadania, conforme figura 2. 
Figura 2. Territórios da Cidadania apoiados pelo PTC

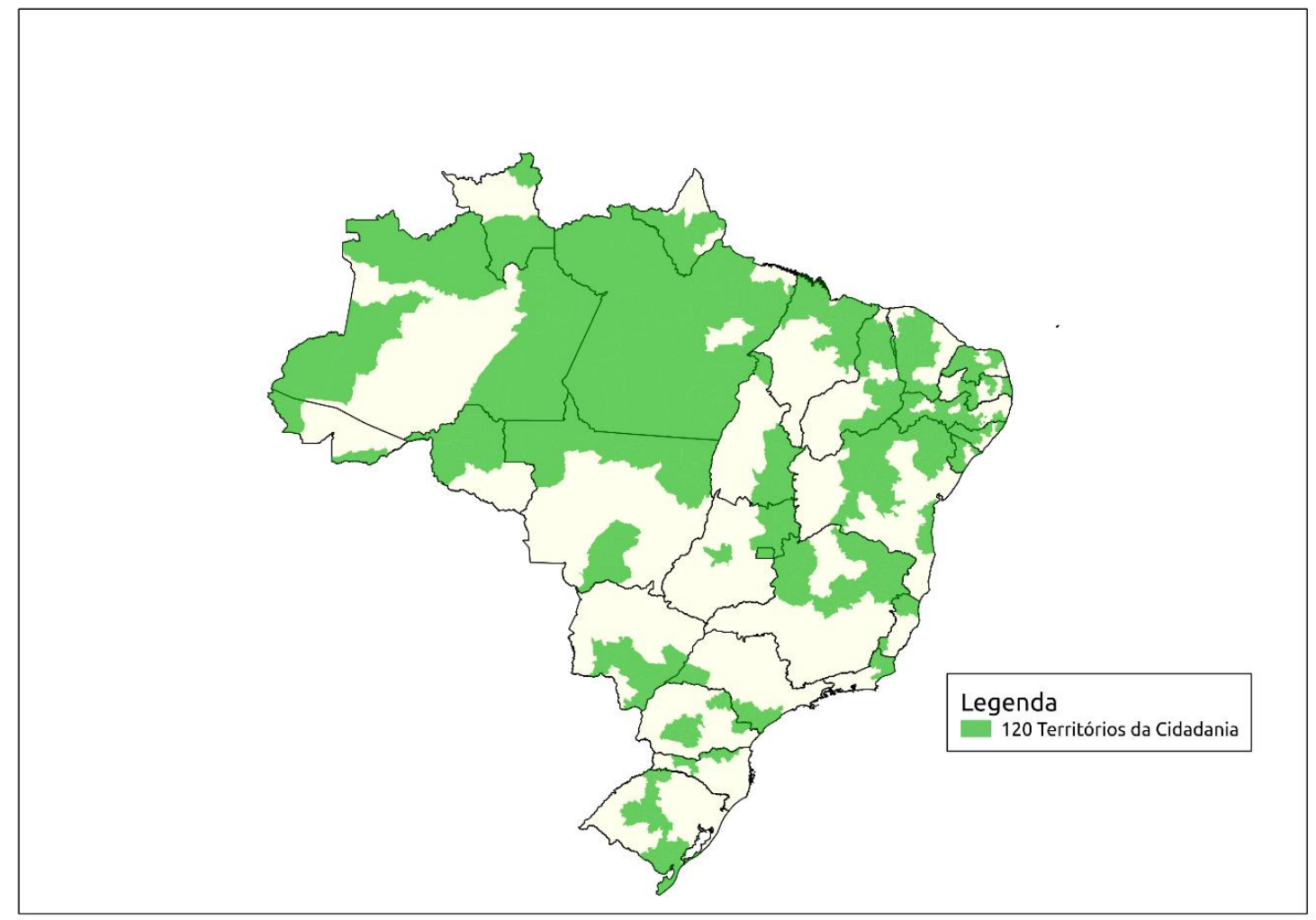

Fonte: SGE, 2014.

A coordenação do Programa era realizada pelo MDA, sua articulação institucional pela Casa Civil, a questão orçamentária pelo Ministério de Planejamento Orçamento e Gestão (MPOG) e o monitoramento pelo Núcleo de Estudos Agrários e Desenvolvimento Rural (Nead) (WESZ JÚNIOR; LEITE, 2010).

Quanto aos recursos destinados ao PTC, os autores apontam que, em $2008 \mathrm{o}$ valor previsto para os 60 Territórios da Cidadania chegou a $\mathrm{R} \$ 12,8$ bilhões, valor que alcançou quase $\mathrm{R} \$ 25$ bilhões em 2009 com a entrada de mais 60 novos territórios. Em 2010 o montante de recursos ampliou-se para R\$26,8 bilhões. Houve portanto, um crescimento de $109,8 \%$ de 2008 para 2010. As linhas com maior crescimento foram (a) organização sustentável da produção e saúde e (b) saneamento e acesso à água, que aumentaram o valor previsto em $187,5 \%$ e $147,7 \%$, respectivamente. O tema que teve uma redução nestes três anos foi o das Ações Fundiárias (27\%).

Entretanto, há vários desafios que se impõe à política territorial do desenvolvimento rural no Brasil. Sabourin (2017), por exemplo, alerta que, apesar da proposta inovadora que traz a abordagem territorial, ainda prevalece uma característica top down, uma postura operacional de reconhecer principalmente as agências estatais como atores da política pública, um significativo afastamento da institucionalidade e dos atores sociais territoriais. Tais características, junto ao arrefecimento da proposta a partir de 2011 na esfera federal, com consequente enfraquecimento das institucionalidades, desarticulações e frustrações dos atores territoriais, dificultaram o avanço da política territorial. O financiamento de infraestruturas e equipamentos coletivos não permite responder a muitos dos problemas estruturais prioritários identificados nos PTDRS. 
Oliveira e Perafán (2012) destacam ainda que em um modelo de gestão participativa, com foco na abordagem territorial, é importante que todos os membros das institucionalidades territoriais saibam, por um lado, planejar de forma estratégica, assim como elaborar propostas, administrar de forma responsável e monitorar ações e projetos considerando elementos de gestão social, tais como: autonomia, inclusão social, inclusão produtiva, garantia de acesso a direitos básicos e formação para uma participação consciente e efetiva nos processos de desenvolvimento dos territórios rurais.

Mostrou-se latente a necessidade de consolidação das instâncias territoriais e execução de ações, de maneira mais autônoma. Um dos fatores que pode explicar essa situação é a maneira de sensibilização e mobilização implementadas para dar início ao ciclo da gestão social nos territórios. Os atores territoriais convocados para a constituição dos Colegiados foram motivados mais pelos recursos para financiamento de projetos e menos para a constituição de um projeto de desenvolvimento territorial apontam Oliveira, Perafán e Conterato (2013). Essa característica pode explicar o fato da maior parte dos Colegiados Territoriais estar desmobilizada desde 2017.

Ortega, Cerqueira e Silva (2016), ressaltam que, apesar das intencionalidades das inovações introduzidas pelas políticas de corte territorial, sua adoção nas estruturas de governança ainda está longe de ser uma realidade. Essa implementação requer a edificação de uma coesão territorial abrangente que crie as condições para a arquitetura de pactos territoriais para o desenvolvimento includente dos segmentos sociais, rurais e urbanos. Acerca desse pacto, pretende-se chamar atenção ao aspecto dos circuitos curtos de comercialização, entendidos aqui como uma importante estratégia para a promoção da soberania e segurança alimentar e nutricional e do desenvolvimento territorial rural.

Apesar de Sabourin, Massardier e Sotomayor (2016) apontarem que na América Latina já estão sendo experimentadas iniciativas que procuram aproximar produtores, mercados de consumidores e agroindústria, percebendo nisto alianças produtivas entre agricultores e agroindústria (Chile, Equador), alianças campesinocozinheiro (Peru), programas de compras públicas aos agricultores familiares (Brasil, Equador, Paraguai, etc.), feiras da agricultura familiar e feiras agroecológicas (Argentina, Brasil, Peru), destaca-se que essa perspectiva não é oficialmente adotada pela política territorial brasileira. Ou seja, apesar da política territorial propor a superação do horizonte estritamente setorial, as dinâmicas de desenvolvimento implementadas carecem avançar nesse aspecto, promovendo maior aproximação campo-cidade e produtor-consumidor.

Assim, para dar sequência à discussão, serão apresentados alguns elementos sobre os circuitos curtos para, em seguida, analisar exemplos de projetos executados nos territórios rurais e da cidadania do Sul do Brasil que permitem pensar uma reconexão entre rural e o urbano como forma de promoção do desenvolvimento rural.

\section{Circuitos curtos de comercialização e as dinâmicas territoriais}

Os processos de desenvolvimento no espaço rural, hegemonicamente, seguem o padrão da modernidade. Retomando Beck (2009), corroboramos com a 
ideia que o paradigma da modernidade encontra-se em crise. A sociedade está sentindo os efeitos e limites do sistema baseado no progresso, na razão, na cientificidade, no individualismo e na busca desenfreada por crescimento econômico - ou seja, na forma de desenvolvimento que dá suporte ao projeto da modernidade. Entende-se que a autoconfrontação da qual trata o autor expressa-se na temática aqui discutida, ao refletir sobre um número crescente de consumidores que optam, sobretudo nos países desenvolvidos, mas não exclusivamente, por alimentos mais saudáveis, locais, frescos, consumidores que substituem o fast food pelo slow food, como aponta a própria FAO (2018).

Alerta Porto Gonçalves (2004) que a ciência tem sido desenvolvida para tornar mais eficiente a produção de biomassa nas regiões temperadas (que dispõem de menor intensidade de energia solar em relação às regiões tropicais). Eis um contrassenso que só se explica pela importância do conhecimento técnico-científico e da regulação jurídica da propriedade (patentes e direitos de propriedade intelectual individual) para os países hegemônicos e para as grandes corporações, que detém o monopólio do conhecimento específico, cada vez mais dependente de recursos para a pesquisa e desenvolvimento.

É por este caminho que se fortalecem os impérios alimentares, entendidos por Ploeg (2008) como o modo de ordenamento fortemente centralizado, constituído por grandes empresas de processamento e comercialização de alimentos, operando em escala mundial. Logo, a globalização agroalimentar ameaça o patrimônio cultural e material agropecuário, rural e alimentar e contribuiu também para aprofundar a crise ecológica na qual vivemos, como destaca Guzmán (2007). Essa alteração do equilíbrio dos agroecossistemas entrelaça-se com os mecanismos de exclusão social que acompanham a acrescente dependência do mercado.

Defende-se aqui, que o alcance da soberania e da segurança alimentar e nutricional não será garantida pelo fortalecimento das cadeias longas, expresso nas projeções do USDA e do MAPA, por meio da exportação de produtos primários ou mesmo commodities processadas. Alimentos saudáveis, diversificados e frescos, que respeitem os hábitos alimentares das diversas populações requer também, um olhar e o estabelecimento de estratégias para o fortalecimento da produção familiar e dos circuitos curtos.

Entende-se ainda que, diante de um contexto de aumento da obesidade e mediante um aumento da demanda mundial por alimentos, esses circuitos ressurgem como uma possibilidade de fomentar economias locais, inclusive periféricas, proporcionar acesso a alimentos variados e frescos, capazes de proporcionar soberania e segurança alimentar e nutricional. Vale ressaltar que na construção e fortalecimento destes circuitos locais de produção-consumo, o papel do consumidor é essencial.

De acordo com Matte et. al (2014), o termo "curto" foi apresentado inicialmente por Terry Marsden (geógrafo e sociólogo) e trata das características que determinado produto apresenta ao chegar ao consumidor, conservando suas informações físicas. A ideia de circuitos curtos não diz respeito somente à distância percorrida pelos alimentos. Segundo Ferrari (2011), as cadeias curtas de alimentos possibilitam um processo de ressocialização ou reespacialização do alimento, possibilitando o julgamento de valor pelo consumidor. Esses novos modelos de comercialização (direta) permitem também a negociação dos melhores preços e a 
retomada do controle das vendas pelos produtores com a qualificação dos consumidores.

A relação com a política territorial brasileira pode ser tecida ao entendermos que os circuitos curtos de comercialização são essenciais para a economia local, para a geração de trabalho e renda e oferta de alimentos saudáveis, conforme proposto pelo objetivo maior do PTC. Ademais, os circuitos de proximidade, segundo Macías (2018), são formas de comercio que incorporam a dimensão territorial, na qual existe uma relação direta, próxima ou de confiança entre produção/produtor, a circulação e o consumo/consumidor. Produção, consumo e sociedade estão relacionados diretamente e qualquer mudança em um deles, gerará mudanças nos demais.

O referido autor sistematiza ainda as qualidades dos circuitos curtos, sendo elas: mantém o valor dos territórios de origem mediante a relocalização, geram empregos, capturam valor a partir do enclave territorial, melhoram a resiliência dos territórios, valorizam o patrimônio, atuam no papel de dinamizador e atração funcional nos territórios, incrementam a apropriação territorial devido a concentração espacial de funções ou a exploração de qualidades de produtos agrícolas. A combinação entre proximidade territorial e circuitos curtos ajudam a fortalecer laços sociais e fomentam a equidade dos intercâmbios comerciais, ao mesmo tempo em que contribuem para a maior autonomia dos atores.

Retomando Schneider e Ferrari (2015), as cadeias curtas apresentam diferentes dimensões, a saber: a) espacial, ao reduzir as distâncias que os alimentos percorrem entre a produção e o consumo; b) social, ao proporcionar o contato face a face entre produtores e consumidores, que resultam em confiança e integração na cadeia; e, c) econômica, ao alavancar mercados locais para a produção.

Em termos práticos, os autores esclarecem que os circuitos curtos podem acontecer através dos produtos produzidos nas pequenas agroindústrias rurais familiares ou em relações face a face, como vendas a domicílio e feiras livres, sejam de produtos da agricultura ou até mesmo de artesanatos (SCHNEIDER; FERRARI, 2015). François (2000), por sua vez, define circuitos curtos enquanto uma forma de comercializar os produtos permitindo diminuir o número de intermediários entre o produtor e o consumidor.

Marsden, Banks e Bristow (2000) acrescentam que os circuitos curtos ocorrem quando um produto chega às mãos do consumidor com informações que Ihe permitam saber sobre o lugar, o produtor e o sistema de produção, ou seja, onde o produto foi produzido, por quem e de que forma. Para os autores, existem três tipos de cadeias curtas (short food supply chains - SFSC), quais sejam:

(i) Proximidade espacial: os produtos são produzidos e distribuídos na região especifica de produção;

(ii) Espacialmente estendida: produtos carregados com valores, significados e informações locais e podem ser comercializados fora da região de produção;

(iii) Face a face: venda direta do produtor para o consumidor, como ocorre nas feiras livres.

Fonseca et. al. (2009) destacam enquanto fortalezas dos circuitos curtos a troca de conhecimentos, saberes e sabores entre produtores, entre produtores e consumidores, entre consumidores. Ainda, tem-se a possibilidade de exercitar melhor o controle social das qualidades orgânicas e das garantias dos produtos 
orgânicos identificadas pelos consumidores devido ao envolvimento produtorconsumidor e as organizações de apoio (públicas, privadas ou da sociedade civil); qualidade esta que se expressa em produtos frescos e com preços menores que nas redes do grande varejo devido à venda direta produtor.

Conforme Darolt et al (2016), uma das especificidades dos circuitos curtos é o questionamento de alguns princípios básicos do sistema convencional, como a homogeneização, a padronização de produtos e o grande número de intermediários na comercialização em grandes distâncias. Nesse sentido, as redes alternativas propõem novos princípios de troca, relocalização dos alimentos, retomam valores, tradições e novos tipos de relações entre produtores e consumidores.

Reportando-se a outros autores, Darolt et al (2016) fazem uma discussão sobre a capacidade dos circuitos curtos gerarem mudanças estruturais em uma escala maior. Defendem que estes mercados podem contribuir para uma transformação das relações de poder no âmbito dos sistemas alimentares, incluindo maior participação de consumidores e produtores na definição dos modos de produção, troca e consumo, o que remete à autonomia.

Entende-se que as características dos circuitos curtos citadas, aproximam estes da perspectiva territorial do desenvolvimento rural, pois ambos aludem a possibilidade de autonomia ou protagonismo dos atores e suas institucionalidades locais. Enfatizam a ligação necessária entre experiências concretas e um movimento social e político de oposição ao modelo convencional dominante (DAROLT et al, 2016). Ainda, visualiza-se que a política territorial tem potencial de contribuir com essa ligação, podendo os Colegiados Territoriais serem os espaços do movimento social e político com as experiências existentes. Uma ação de fundo, fomentando os circuitos curtos, poderia ser a base da constituição dos projetos de desenvolvimento territorial, ainda pouco consolidados, como já apontado por Oliveira, Perafán e Conterato (2013). Corroboram Darolt et al (2016), que o aprendizado proporcionado pelos circuitos, as práticas agrícolas e seus impactos, as práticas culinárias e as práticas democráticas em si envolvem pessoas e instituições e são fontes de empoderamento dos consumidores, contribuindo para torná-los cidadãos conscientes de sua alimentação ou consumidores cidadãos.

Ressalta-se que, apesar de a política territorial envolver uma visão integradora de espaços, atores sociais, mercados e políticas públicas de intervenção, o consumidor é um ator desconsiderado nessa dinâmica. Tais ações de reconexão com o local deveriam perpassar os objetivos da própria política territorial. Considerar o consumidor enquanto um ator social e integrá-lo às dinâmicas territoriais parece fundamental para o desenvolvimento do território e suas especificidades socioculturais, político, econômico e ambientais. Vem ao encontro deste apontamento a observação de Macías (2018), quando trata das modalidades de apropriação coletiva do território onde se produzem e consomem os alimentos por parte de grupos de consumo emergentes. Afirma que o lugar, a distância e as novas modalidades de interface rural-urbana, emergem como dimensões territoriais particulares as quais agregam valor adicional a cultura do consumo alimentar tradicional.

Mediante o mencionado, serão analisados os projetos implementados em dois territórios rurais e um da cidadania na região Sul do Brasil, apontados pelos membros dos Colegiados como "projetos com maiores repercussões territoriais" no 
desenvolvimento rural, evidenciando que estes são representativos de circuitos curtos de comercialização.

\section{Metodologia de pesquisa}

Este artigo é oriundo de uma pesquisa financiada pelo edital MCTI/CNPq/MEC/CAPES $N^{\circ}$ 43/2013. Como caminho metodológico, foi realizada inicialmente uma pesquisa bibliográfica a partir de documentos oficiais acerca das políticas de desenvolvimento regional e territorial que permitiram elencar as características, objetivos e ações que constituem essas políticas. Especificamente para este trabalho, o foco deu-se na política territorial.

A partir destas informações, foi realizada pesquisa de campo nos três estados do Sul do Brasil, a saber, Rio Grande do Sul, Santa Catarina e Paraná, onde foram identificados dois territórios rurais (PR e SC) e um território da cidadania (RS). Foram realizadas 15 entrevistas com membros que compõem o Fórum da Mesorregião da Grande Fronteira do Mercosul (referente à Política Nacional de Desenvolvimento Regional/PNDR) e os Colegiados Territoriais, além de beneficiários de projetos.

Tratou-se assim, de uma pesquisa qualitativa, baseada em um estudo de casos múltiplos. A escolha dos territórios baseou-se no critério de sobreposição das regionalizações da PNDR e da política territorial. Dentre todos os territórios possíveis, optou-se por aqueles de mais fácil acesso aos pesquisadores. Solicitou-se que os membros dos Colegiados indicassem o projeto mais exitoso ou que melhor representasse a dinâmica territorial. Desse modo, foram pesquisados pelo Pronat o projeto de vitivinicultura no território rural Sudoeste Paranaense e o Programa Sistema Unificado de Atenção à Sanidade Agropecuária (Prosuasa) no município de Chapecó (SC) no território rural Oeste Catarinense. Já pelo PTC, no território da cidadania Médio Alto Uruguai, foi analisado o projeto de fortalecimento da agricultura familiar através da cadeia produtiva do leite. Utilizou-se como instrumento de coleta de dados entrevistas semiestruturadas.

\section{Considerações sobre os projetos de desenvolvimento territorial representativos de circuitos curtos na região Sul do Brasil}

Os projetos analisados na seção 4 foram indicados como sendo aqueles que tiveram mais repercussões territoriais pelos próprios entrevistados. 0 estudo destes projetos, enfatizando a abordagem dos circuitos curtos de comercialização, permite evidenciar, de forma empírica, transformações territoriais geradas pela política de desenvolvimento territorial rural, em regiões que até recentemente não haviam sido foco de políticas públicas de desenvolvimento. Além de incluir regiões, também foi possibilitado aos atores locais/regionais, uma atuação mais ativa e protagonista sobre a definição das ações de desenvolvimento rural, como apontamos em Rambo et al (2017), regiões e atores estes, que historicamente foram submetidos às tradicionais estratégias de desenvolvimento rural.

\subsection{Associação dos Produtores Vitivinicultores de Verê (Aprovive) - Paraná}

No território rural Sudoeste Paranaense foi analisado o projeto de vitivinicultura da Associação dos Produtores Vitivinicultores de Verê (Aprovive), 
localizada no município de Verê/PR, iniciativa que tem início antes mesmo da criação do Pronat. A figura 3 que segue apresenta a localização do território.

\section{Figura 3. Territórios Rurais no Paraná - Território Sudoeste Paranaense}

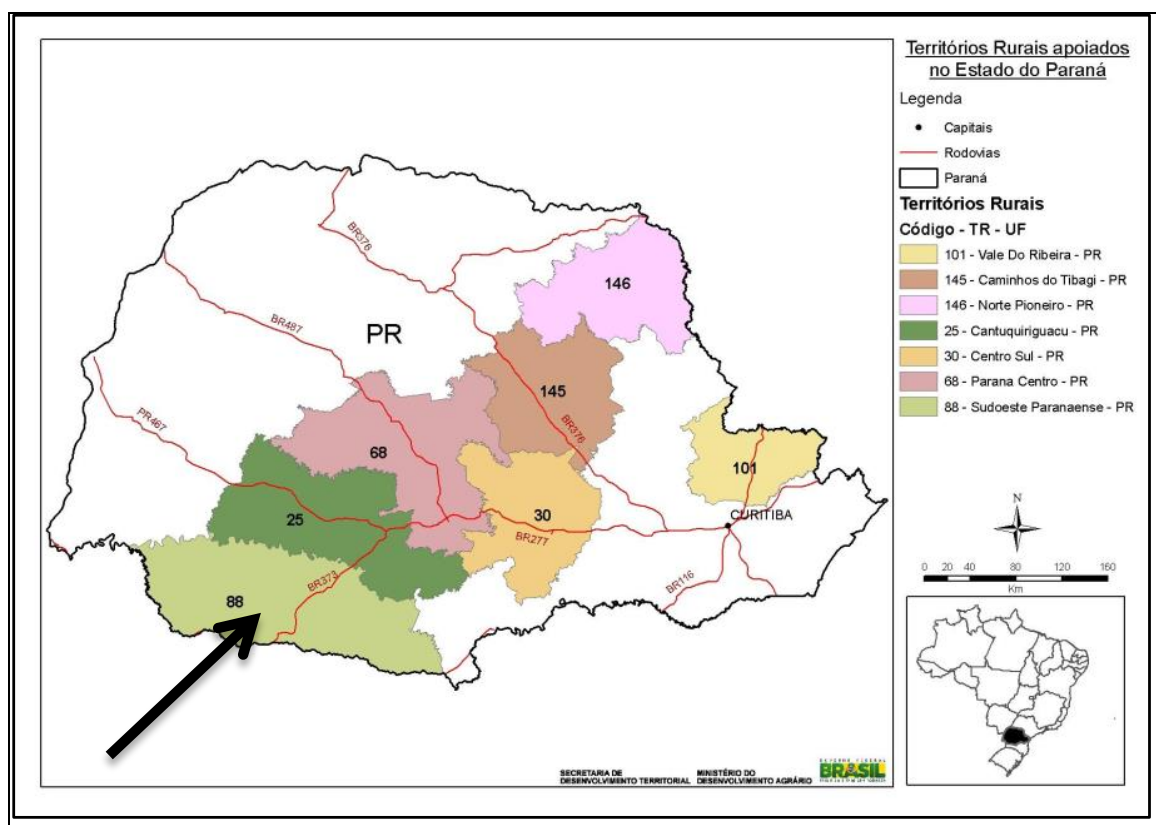

Fonte: Adaptado de SIT (2018).

No ano 2000, uma empresa de SC, exportadora de sucos concentrados, propôs implementar um projeto de parreirais em propriedades do município. Porém, no ano de 2002 a empresa decretou falência e os agricultores ficaram sem apoio e sem mercado para sua produção. Diante dessa situação, os vitivinicultores criaram a Aprovive, visando dar um destino à produção de uva.

Entre 2004/2005, em uma parceria com a prefeitura municipal de Verê, foi implementada a Indústria de Sucos Viry para comercializar uva e fabricar vinhos (GAIOVICZ, SAQUET, 2010). Como a variedade cultivada não era propícia à produção de vinhos, o poder público municipal fez parceria com o Centro de Apoio e Promoção da Agroecologia (Capa) para que este fornecesse assistência técnica. Em contrapartida, o Capa exigiu que a produção convencional de uvas fosse convertida em orgânica.

Conforme entrevistas realizadas com membros desse território do PR, as 12 famílias envolvidas processam de cinco a seis mil quilos de uvas, chegando a produzir 50.000 litros de suco de uva orgânico, comercializados para 25 municípios da região, destinados principalmente para a alimentação escolar. As sobras da uva são encaminhadas à Associação de Produtores Agroecológicos de Verê (Apav), onde são transformadas em geleias. O mesmo ocorre com a produção da polpa para suco, em saquinhos. Os produtos da Apav são comercializados na associação, para alimentação escolar e em alguns mercados fora do município, como em Curitiba (GAIOVICZ, SAQUET, 2010). Na figura 4 é possível visualizar imagens do projeto no Sudoeste Paranaense.

Figura 4. Indústria Viry e parreiral orgânico 


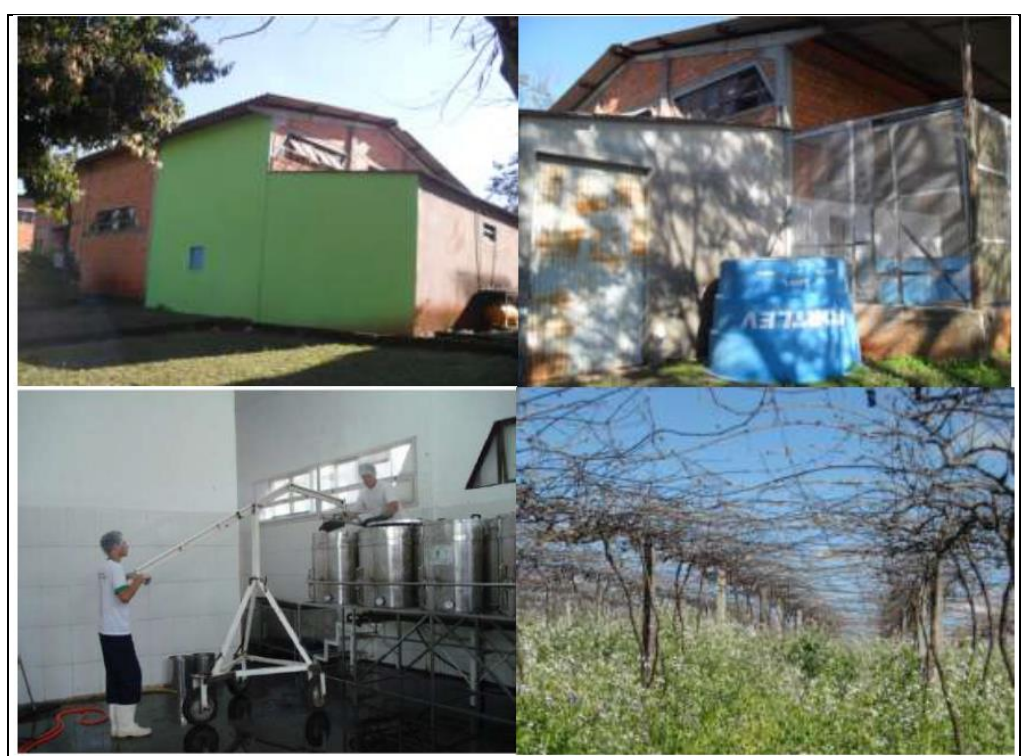

Fonte: Arquivo pessoal (2016), Gaiovicz, Saquet (2010), Gaiovicz (2010).

Retomando Marsden, Banks e Bristow (2000), podemos observar a Aprovive como um modelo de circuito curto que se caracteriza pela "proximidade espacial", uma vez que seus produtos são comercializados na região e por ser "espacialmente estendido", quando a comercialização alcança a cidade de Curitiba/PR.

Verifica-se ainda, pela trajetória da associação, que com a parceria com o Capa há, conforme Darold et. al (2016), um questionamento ao sistema convencional de produção, possibilitando assim a mudança para um produto diferenciado, com maior qualidade nutricional e ambiental. Cria-se a possibilidade de exercitar melhor o controle social das qualidades orgânicas e das garantias dos produtos orgânicos identificadas pelos consumidores devido ao envolvimento produtor-consumidor e as organizações de apoio tal como enfatizam Fonseca et. al. (2009)

\subsection{Programa do Sistema Unificado de Atenção à Sanidade Agropecuária (Prosuasa) - Santa Catarina}

No Território Rural do Oeste Catarinense, foi indicado o Programa do Sistema Unificado de Atenção à Sanidade Agropecuária (Prosuasa). Iniciado em 2012, teve por objetivo viabilizar o credenciamento de agroindústrias junto ao Sistema Brasileiro de Inspeção de Produtos de Origem Animal/Sistema Unificado de Atenção à Sanidade Agropecuária (SISBI/SUASA), na área de abrangência do Consórcio Intermunicipal de Desenvolvimento Econômico, Social e do Meio Ambiente (Cidema). Este credenciamento visa à ampliação dos mercados das agroindústrias (produtos de origem animal) para além do território municipal. A figura 5 destaca a localização deste território rural.

Figura 5. Territórios Rurais de Santa Catarina - Território Oeste Catarinense 


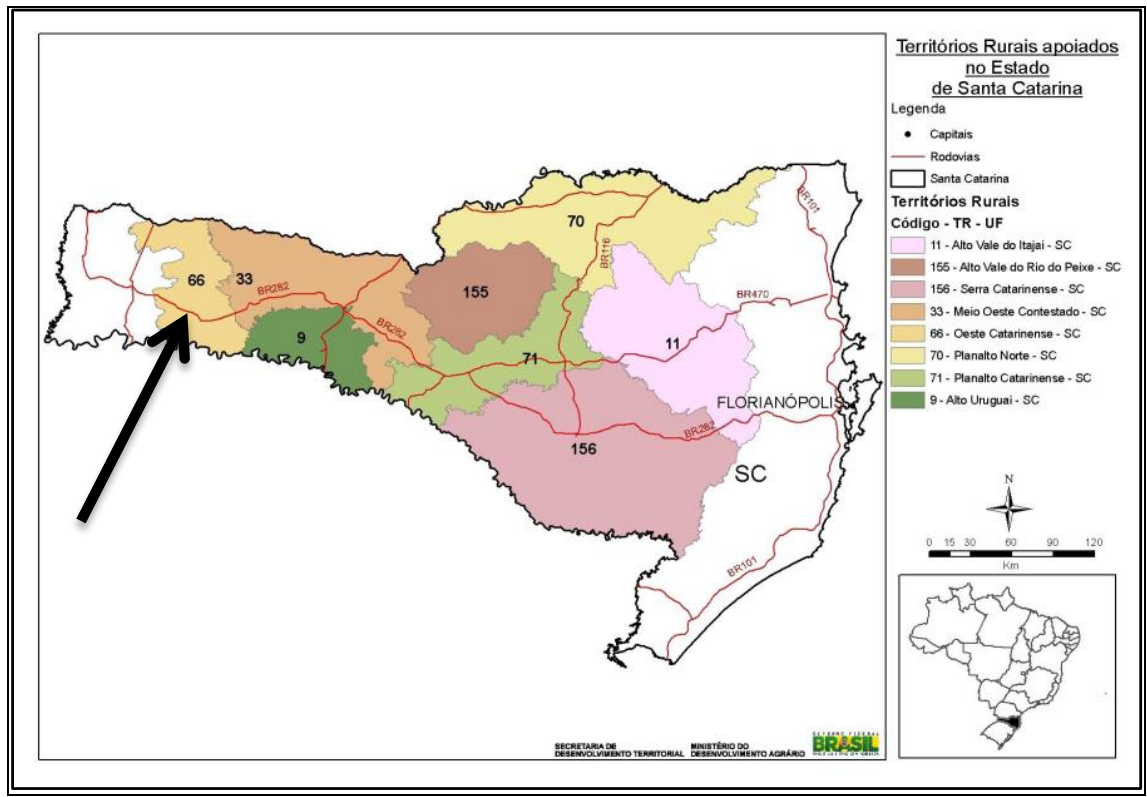

Fonte: Adaptado de SIT (2018).

No território, foi estabelecida parceria do Cidema com a Agência Saga e feito um diagnóstico que apontou interesse de 52 agroindústrias na obtenção do Suasa. Conforme entrevistado do Colegiado: "E ai nós pegamos o recurso para fortalecer os sistemas municipais, o recurso deu na época para comprar um carro para cada município para o veterinário atuar na inspeção municipal, então esse era o propósito do projeto" (Entrevista 12 - membro da Amosc e Colegiado Territorial).

Segundo o SGE, foi liberado, em 2012, um montante de $\mathrm{R} \$ 438.735,71$ para estruturar o Cidema, fortalecendo os sistemas municipais de inspeção, com a aquisição de carros para atuação dos veterinários em seus respectivos municípios.

Segundo entrevistas, são três agroindústrias credenciadas pelo Prosuasa: uma de ovos no município de São Carlos, uma de derivados de carne (hamburger) em Coronel Freitas e outra agroindústria de ovos em Cordilheira Alta, como ilustrado na figura a seguir. 
Figura 6. Agroindústria de ovos e carnes beneficiadas com o Prosuasa
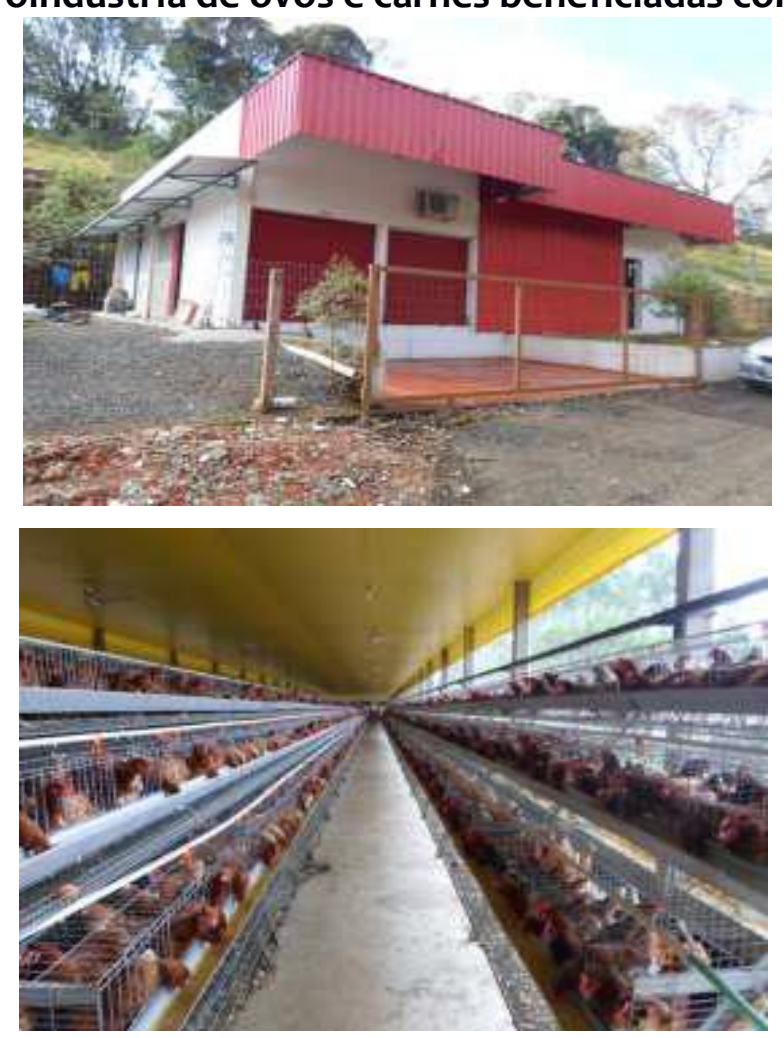

Fonte: Cidema/Trabalho de campo, 2016.

Este projeto tende a construir um circuito curto na escala regional, o que pode ser corroborado com a fala de um dos entrevistados: “(...) esse de São Carlos, ele tinha um comércio dele local, produzia e tinha 8 mil matrizes para produzir ovos. No ano seguinte que ele credenciou e já estava com 30 mil matrizes, e tem potencial ainda mais para crescer, (...) o mercado para esse tipo de estabelecimento ele tem, desde que se organize e se estruture, então a nossa contribuição enquanto consórcio é, primeiro, fortalecer um projeto de desenvolvimento regional, dar condição para o pessoal acessar o mercado e de ter valor agregado a sua produção, é uma forma de fixar aquele cidadão lá no campo... (Entrevista 12 - membro da Amosc e Colegiado Territorial, 2016).

Com este relato nota-se que com uma reconfiguração institucional local tem sido possível ampliar o comércio das agroindústrias, principalmente aquelas que conseguiram, via consórcio, credenciarem-se no SISBI/SUASA. Segundo Schneider e Ferrari (2015), a adequação burocrática das agroindústrias permite com que estas entrem no mercado formal e, ao mesmo tempo, alavanquem os mercados locais para a produção de alimentos de origem animal, o que foi promovido através dos recursos da política dos territórios rurais em SC.

Desse modo, o Prosuasa, no recorte espacial do Cidema, tem o potencial de contribuir para uma transformação das relações de poder no âmbito dos sistemas alimentares de produtos de origem animal, incluindo maior participação de consumidores e produtores na definição dos modos de produção, troca e consumo, o que remete à maior autonomia desses atores, como mencionam Darolt et al (2016)

\subsection{Fortalecimento da agricultura familiar através da cadeia produtiva do leite - RS}


No território da cidadania Médio Alto Uruguai foi destacado o projeto Fortalecimento da Agricultura Familiar através da Cadeia Produtiva do Leite, eleito como sendo a prioridade nas ações territoriais, a partir de 2010. A localização do território é apresentada na figura 7 abaixo.

Figura 7. Territórios da Cidadania do Rio Grande do Sul - Território Médio Alto Uruguai

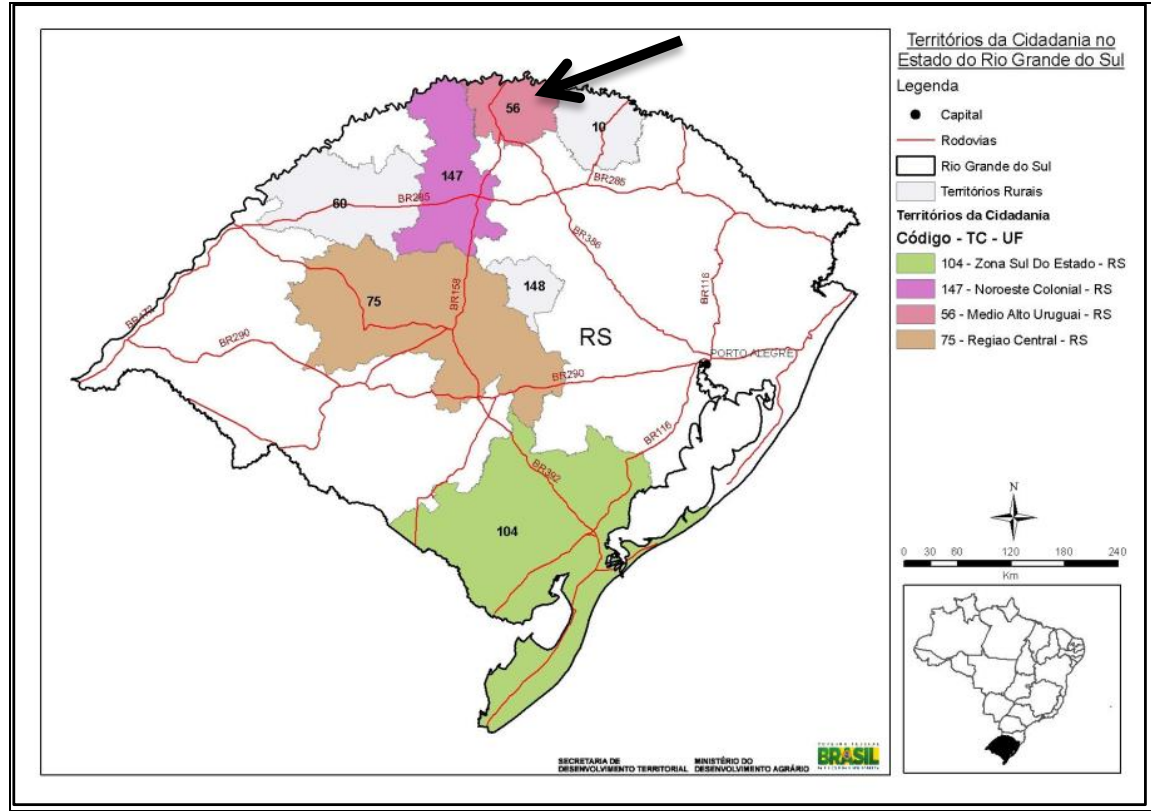

Fonte: Adaptado de SIT (2018).

Dentre os diferentes incentivos à produção leiteira, um deles se refere à construção do Laboratório de Análise de Alimentos e Bebidas (LAAB), localizado nas dependências da Universidade Regional Integrada (URI), campus de Federico Westphalen (RS). O laboratório tem condições de prestar serviços para a cadeia do leite e derivados, e também pode realizar análises em diferentes tipos de amostras, como produtos cárneos e derivados e produtos de nutrição animal, dentre outros, realizando ensaios microbiológicos e físico-químicos. A figura 8 abaixo ilustra o laboratório descrito. 


\section{Figura 8. Equipamentos do Laboratório de Análise de Alimentos e Bebidas (LAAB)}

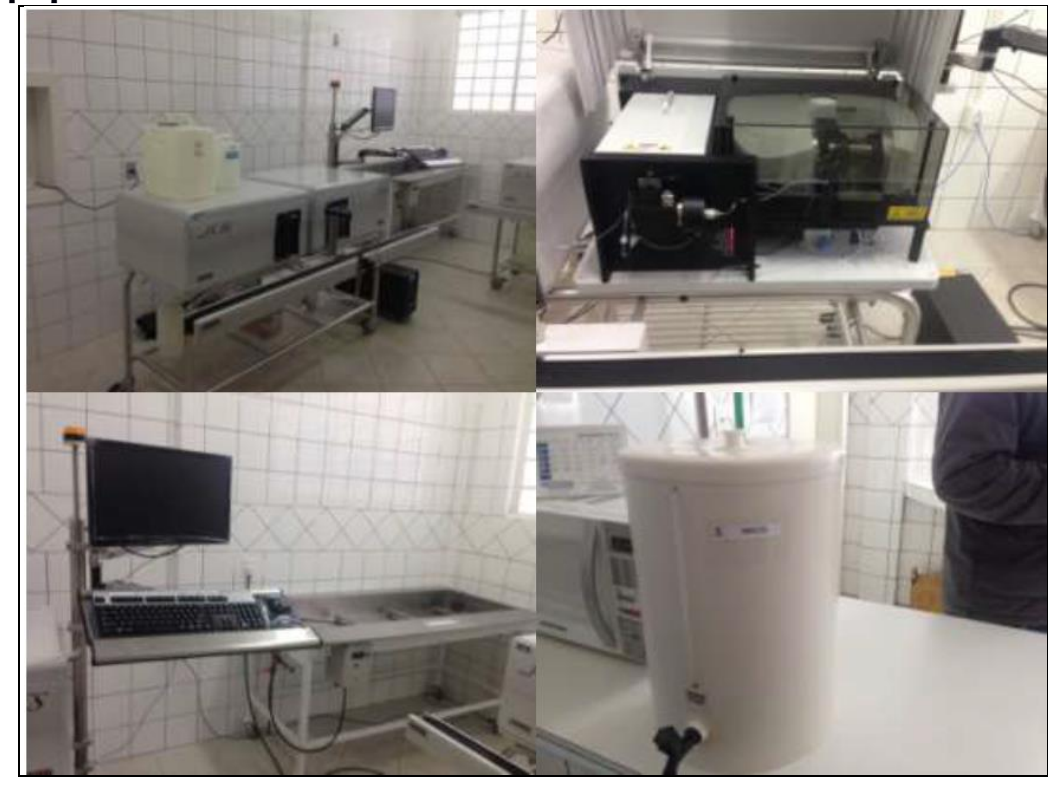

Fonte: acervo pessoal, 2016.

A proposta do laboratório de análise de leite é enfrentar o desafio de viabilizar o processo industrial de boa parte do leite produzido na região, melhorando a apropriação de renda para os agricultores, cooperativas, associações de produtores e seus municípios (URI, 2016). Atualmente, os laboratórios oficiais mais próximos localizam-se nos municípios de Lajeado, Passo Fundo ou Curitiba. Devido à distância, ocorrem problemas com a qualidade das amostras que chegam aos laboratórios, impossibilitando as análises. Ou seja, este projeto, ao propor realizar análises do leite na própria região, tende a empoderar os atores locais/regionais, diminuindo custos de produção e qualificando o produto local.

O laboratório, de forma imediata, contribui para os circuitos longos, uma vez que a cadeia produtiva do leite caracteriza tal circuito - produtos padronizados, desenraizados, com diversos intermediários entre produtor e consumidor encontrando-se estruturada na região. Porém, abre a possibilidade de implementação e fortalecimento de circuitos curtos, como fornecimento de leite e derivados, bem como produtos cárneos e seus derivados, para consumo local/regional, dentre outras possibilidades, para alimentação escolar.

A existência de um laboratório de análises microbiológicas e físico-químicas é essencial para que o leite produzido localmente também possa ser processado e consumido na mesma escala. Desse modo, será possível agregar valor ao produto do agricultor familiar, gerar emprego e renda, explorar as qualidades dos produtos, fortalecendo laços sociais e fomentando a equidade dos intercâmbios comerciais, ao mesmo tempo em que contribui para a maior autonomia dos atores, tal como exposto por Macías (2008).

Dados os projetos acima apresentados, inferimos que política territorial tem financiado circuitos curtos, cujos atores envolvidos frequentemente acessam outras políticas que também incentivam estes circuitos, como o Programa Nacional de Alimentação Escolar (PNAE) o Programa de Aquisição de Alimentos (PAA) e mesmo ações da Política Nacional de Assistência Técnica e Extensão Rural (PNATER). Os projetos analisados demonstram uma valorização e dinamização dos territórios na 
medida em que fazem girar a economia local, fomentam a equidade dos intercâmbios comerciais e fortalecem laços sociais, ao mesmo tempo em que contribuem para a maior autonomia dos atores envolvidos.

$\mathrm{Na}$ medida em que a política territorial assumir a criação e o fomento dos circuitos curtos de comercialização enquanto objetivo que perpasse os demais, agregando ações para com o público consumidor, será possível qualificar a dimensão territorial das políticas de desenvolvimento rural.

Vale ressaltar que na construção e fortalecimento destes circuitos locais de produção-consumo, o papel do consumidor é essencial. Os consumidores devem tomar consciência de que sua qualidade de vida está intimamente associada aos modelos agrícolas e seus múltiplos serviços ambientais. Ações nesse sentido são imprescindíveis a uma política de caráter territorial, já que se cria a possibilidade de fortalecer identidade e coesão social, cultural e territorial, integrando urbano e rural (ORTEGA; CERQUEIRA; SILVA, 2016).

\section{Considerações finais}

Buscou-se chamar atenção neste trabalho sobre a contribuição dos circuitos curtos de comercialização que reconectam produtores e consumidores, para a promoção da soberania e segurança alimentar e nutricional, em especial em um cenário de aumento de fome por um lado, e do sobrepeso e obesidade por outro. As tradicionais estratégias de desenvolvimento rural têm buscado inserir os agricultores, inclusive os familiares, nos mercados caracterizados por circuitos longos, vide Relatório Projeções do Agronegócio - Brasil 2016/17 a 2026/27, que propõe o aumento da exportação de commodities brasileiras. Este modelo hegemônico pode contribuir para diminuir a fome, mas é questionável sua contribuição para a soberania e segurança alimentar e nutricional dos povos. Dificilmente será possível fornecer alimentos frescos, diversificados e adequados à cultura alimentar local/regional a partir de circuitos longos. Da mesma forma, a manutenção da biodiversidade agroecossistêmica é colocada em cheque.

Unidades produtivas pequenas e biodiversificadas apresentam economias mais saudáveis e menores problemas sociais. Tem-se observado que há consumidores em busca de alimentos respaldados em valores intrínsecos associados à agricultura familiar: frescos, orgânicos, artesanais, territoriais, com indicação geográfica, sustentáveis, etc. Ampliar isso é importante tanto para o bem-estar de quem produz como para quem consome e para o meio ambiente. É importante que as políticas públicas considerem o papel do consumidor nesse processo de reconstrução da relação com a produção de alimentos. Por outro lado, os consumidores necessitam também tomar consciência de que sua qualidade de vida está intimamente associada aos modelos agrícolas e seus múltiplos serviços ambientais. Ou seja, produção, consumo e sociedade estão diretamente relacionados e qualquer mudança em um deles, gerará mudanças nos demais, além de repercutir na dinâmica territorial de desenvolvimento rural.

Paralelo a essa discussão, há dois programas que se valem da perspectiva territorial do desenvolvimento rural que, além de estarem paralisados pelo Governo Federal, não incorporaram a promoção de circuitos curtos aos seus objetivos, princípios e metodologia, tampouco abarcaram o consumidor enquanto um ator 
essencial para a promoção de dinâmicas socioculturais, ambientais e econômicas nos territórios. Apesar de os projetos expostos na seção 4 fomentarem, de algum modo, circuitos curtos e, a política territorial apoiar a superação do horizonte estritamente setorial, as dinâmicas de desenvolvimento analisadas carecem avançar nesse aspecto, sendo que poderiam promover maior aproximação campo-cidade e produtor-consumidor, ampliando as institucionalidades que amparam tais dinâmicas.

Circuitos curtos agroalimentares dinâmicos e consolidados reverberam em maior soberania e segurança alimentar e nutricional, constituindo um mosaico escalar de territórios. Entende-se que este seja um meio para a edificação de uma coesão territorial que crie as condições para a arquitetura de pactos territoriais para o desenvolvimento includente dos segmentos sociais, rurais e urbanos, contribuindo para o alcance dos ODS, em especial ao que se refere ao número 2: acabar com a fome, alcançar a segurança alimentar e melhoria da nutrição e promover a agricultura sustentável.

\section{REFERÊNCIAS}

BECK, U. World at Risk. Cambridge: Polity Press, 2009.

BRASIL. Sistema de Informações Territoriais. 120 territórios da cidadania. 2011. Disponível em:

<http://sit.mda.gov.br/images/mapas/tc/br_055_tcs_120_maio_2009.jpg>. Acesso em 10 jul.2011.

BRASIL. Secretaria do Desenvolvimento Territorial. Balanço do Pronat marca a semana da agricultura familiar. Brasília: 2010. Disponível em: <http://www.mda.gov.br/portal/sdt/noticias/item?item_id=6191472>. Acesso em nov. 2013.

BRASIL. Referências para o apoio ao desenvolvimento territorial. Brasília: MDA/SDT, 2004. Disponível em:<http://www.facesdobrasil.org.br/.../239-programanacional-de-desenvolvimento-...>. Acesso em nov. de 2013.

DAROLT, M. R. et al. Redes alimentares alternativas e novas relações produçãoconsumo na França e no Brasil. Ambiente \& Sociedade, São Paulo v. 19, n. 2, p. 1-22 abr.-jun. 2016.

FACCO, V. A. B. Alternativas aos impérios agroalimentares a partir do campesinato agroecológico: as experiências do acampamento agroflorestal José Lutzenberger (MST-Antonina/PR), Revista NERA, Presidente Prudente, Ano 18, nº 29 p. 70-100 JulDez./2015.

FAO. Food and Agriculture Organization of the United Nations. Representante da FAO Brasil apresenta cenário da demanda por alimentos. Disponível em:< http://www.fao.org/brasil/noticias/detail-events/en/c/901168/>. Acesso em ago/2018. 
FONSECA, M. F. A. et al. Características, estratégias, gargalos, limites e desafios dos circuitos curtos de comercialização de produtos orgânicos no Rio de Janeiro: as feiras. Revista Brasileira de Agroecologia, v. 4, n. 2, p. 2.599-2.602, 2009.

FRANÇOIS, Martine. Comercializar os produtos locais: circuitos curtos e circuitos longos. Inovação no meio rural. Caderno $\mathbf{n}^{\circ} \mathbf{7}$. Observatório Europeu LEADER. Julho de 2000.

GAIOVICZ, E. F. SAQUET, M. A. Poder e identidade: as entidades da agroecologia no município de Verê - Sudoeste do Paraná. Anais do XVI Encontro Nacional de Geografia, Porto Alegre: 2010.

GAZOLLA, M.; SCHNEIDER, S. A produção da autonomia: os "papéis" do autoconsumo na reprodução social dos agricultores familiares. Estudos Sociedade e Agricultura, Rio de Janeiro, v. 15, n. 1, p. 89-122, 2013.

\section{. (org). Cadeias curtas e redes agroalimentares}

alternativas: negócios e mercados da agricultura familiar. Porto Alegre: Editora da UFRGS, 2017.

GUZMAN, Eduardo Sevilla; Agroecología y soberanía alimentaria: alternativas a la globalización agroalimentaria. Patrimonio cultural en la nueva ruralidade, $\mathbf{P h}$ Cuadernos, 2007, 191. Disponível em: <http://www.iaph.es/export/sites/default/galerias/documentacion_migracion/Cuade rno/1279619840882_agroecologia_y_soberania_alimentaria.pdf > Acesso em: $\mathrm{mar} / 2018$.

MACÍAS, Javier D. Ciruitos alimetarios de proximidade. Um acercamiento al anclaje territorial de formas emergentes de producción y consumo rururbanas. In:

PERAFÁN, Mireya E. V. Gestão e Dinâmicas em Desenvolvimento Territorial. Curitiba: CRV, 2018.

MAPA. Ministério da Agricultura, Pecuária e Abastecimento. Projeções do Agronegócio Brasil 2016/17 a 2026/27. Disponível em: <http://www.agricultura.gov.br/assuntos/politica-agricola/todas-publicacoes-depolitica-agricola/projecoes-do-agronegocio/projecoes-do-agronegocio-2017-a-2027versao-preliminar-25-07-17.pdf>. Acesso em: ago/2018.

MARSDEN, T.; BANKS, J.; BRISTOW, G. Food suply chain approaches: exploring their role in rural development, Sociologia Ruralis, 2000, vol. 40, n. 4, pp. 424-438.

MATTE, A.; NESKE, M. Z.; BORBA, M. F .S.; WAQUIL, P. D. \& SCHNEIDER, S. (2014) A relocalização e o mercado de cadeias curtas na pecuária familiar do território Alto Camaquã no sul do Rio Grande do Sul. En: $7^{\circ}$ Encontro de Economia Gaúcha. PUC, Porto Alegre. 
OLIVEIRA, Carlos D.; PERAFÁN, Mireya E.; CONTERATO, Marcelo A. Percepção de atores sociais sobre gestão estratégica e gestão social no âmbito da Política de Desenvolvimento Territorial no Brasil. Desenvolvimento Regional em Debate, Canoinhas, Ano 3, n. 2, p. 154-175, out. 2013.

OLIVEIRA, C. D. S.; PERAFÁN, M. E. V. Gestão social no âmbito do Programa Desenvolvimento Sustentável de Territórios Rurais. In: Encontro da Rede de Estudos Rurais. Belém: Rede de Estudos Rurais, 2012.

ORTEGA, A. C.; CERQUEIRA C. A. de; SILVA, F. P. M. da. As políticas públicas de desenvolvimento no estado da Bahia: evolução e características. In: ORTEGA, A. C.; PIRES, M. J. de S. As políticas territoriais rurais e a articulação governo federal e estadual: um estudo de caso da Bahia. Brasília: Ipea, 2016.

PLOEG, J. D. V. D. Camponeses e impérios alimentares. Porto Alegre, editora da UFRGS, 2008.

PORTO GONÇALVES, C. W. Geografia da riqueza, fome e meio ambiente: pequena contribuição crítica ao atual modelo agrário/agrícola de uso dos recursos naturais. Interthesis, Florianópolis, v. 1, n. 1, 2004.

RAMBO, A. G. Repercussões territoriais decorrentes da política nacional de desenvolvimento regional e da política territorial de desenvolvimento rural na região Sul do Brasil. In: CONGRESSO DA SOCIEDADE BRASILEIRA DE ECONOMIA, ADMINISTRAÇÃO E SOCIOLOGIA RURAL, 55, 2017, Santa Maria. Anais..., Santa Maria: Sober, 2017.

SABOURIN, Eric. Desenvolvimento territorial e políticas públicas no Brasil. 2017. Disponível em <http://agritrop.cirad.fr/584046/1/Sabourin\%2opoliticas\%20de\%20DTR\%20Juazeiro\%20 UFCA.pdf $>$. Acesso em Jan/2018.

SABOURIN, E. P., MASSARDIER, G.; SOTOMAYOR, O. As políticas de desenvolvimento territorial rural na América latina: uma hibridação das fontes e da implementação, Mundos Rurales, v. 3, n.1, p.75-98, mayo/2016.

SCARABELOT, M. \& SCHNEIDER, S. (2012) As cadeias agroalimentares curtas e desenvolvimento local: Um estudo de caso do município de Nova Veneza, SC. Revista Faz Ciência V.15 (20). 101-130.

SCHNEIDER, S. \& FERRARI, D. L. (2015) Cadeias curtas, cooperação e produtos de qualidade na agricultura familiar: o Processo de Relocalização da Produção Agroalimentar em Santa Catarina. Organizações Rurais \& Agroindustriais. V. 17(1). 56-71. 
SILVA, Monica Nardine et. al. A agricultura familiar e os circuitos curtos de comercialização de alimentos: estudo de caso da feira livre do município de Jaguarão, RS, Brasil. Revista Espacios, Vol. 38 ( $\left.\mathrm{N}^{\circ} 47\right)$ Ano 2017.

SIT. Sistema de Informações Territoriais. Disponível em:<sit.mda.gov.br/>. Acesso em: nov/2018.

URI. Inauguração do Laboratório do Leite acontece hoje. Disponível em: http://www.fw.uri.br/site/noticia/860/inauguracao-do-laboratorio-de-analise-doleiteacontece-hoje. Acessado em: 15.09.2016.

Anelise Graciele Rambo. Doutora em Desenvolvimento Rural (UFRGS). Mestre em Geografia (UFRGS). Graduada em Geografia (UNIJUI). Docente do Programa de Pós-graduação em Dinâmicas Regionais e Desenvolvimento (PGDREDES) da UFRGS. anelise.rambo@ufrgs.br

Tanise Dias Freitas. Doutora em Sociologia (UFRGS). Mestre em Ciências Sociais (UFSM). Graduada em Ciências Sociais (UFSM). Pós-doutoranda no Programa de Pós-Graduação em Desenvolvimento Regional da UNISC.tanisef@unisc.br

Como citar: RAMBO, Anelise Graciele; FREITAS, Tanise Dias. Reconexão entre produção e consumo de alimentos e a política territorial de desenvolvimento rural no Brasil. Redes, Santa Cruz do Sul, v. 24, n. 3, p. 118-141, set. 2019. ISSN 1982-6745. Disponível em: https://doi.org/10.17058/redes.v24i3.14121. 